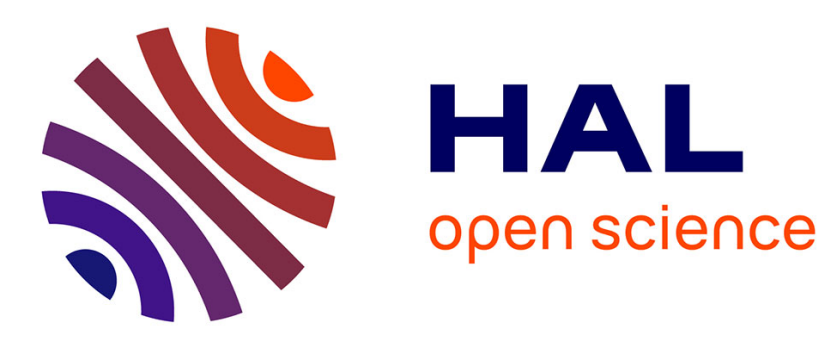

\title{
Ionization Mechanism in a Thermal Spark Discharge
}

Nicolas Minesi, Pierre Mariotto, Gabi-Daniel Stancu, Christophe O Laux

\section{To cite this version:}

Nicolas Minesi, Pierre Mariotto, Gabi-Daniel Stancu, Christophe O Laux. Ionization Mechanism in a Thermal Spark Discharge. AIAA Scitech 2021 Forum, Jan 2021, VIRTUAL EVENT, France. 10.2514/6.2021-1698 . hal-03103724

\section{HAL Id: hal-03103724 \\ https://hal.science/hal-03103724}

Submitted on 28 Jan 2021

HAL is a multi-disciplinary open access archive for the deposit and dissemination of scientific research documents, whether they are published or not. The documents may come from teaching and research institutions in France or abroad, or from public or private research centers.
L'archive ouverte pluridisciplinaire HAL, est destinée au dépôt et à la diffusion de documents scientifiques de niveau recherche, publiés ou non, émanant des établissements d'enseignement et de recherche français ou étrangers, des laboratoires publics ou privés. 


\title{
Ionization Mechanism in a Thermal Spark Discharge
}

\author{
Nicolas Q. Minesi*, Pierre B. Mariotto ${ }^{\dagger}$, Gabi-Daniel Stancu ${ }^{\ddagger}$, \\ and Christophe O. Laux ${ }^{\S}$ \\ EM2C, CNRS, CentraleSupélec, Université Paris Saclay, 3 Rue Joliot-Curie, \\ 91190 Gif-sur-Yvette, France
}

The formation of thermal sparks generated by nanosecond pulses is studied experimentally and numerically. The increase of the electron number density, up to $10^{19} \mathrm{~cm}^{-3}$, is measured with sub-nanosecond resolution using Stark broadening of $\mathrm{N}^{+}$, Stark broadening of $\mathrm{H}_{\alpha}$, continuum emission of the electron, and the intensity of $\mathrm{N}^{+}$lines. Our experimental results are then compared to 0-D kinetic simulations including the electron-impact ionization of excited electronic states of $\mathrm{N}$ and $\mathrm{O}$. The electron temperature, in equilibrium with the gas temperature, reaches $42,000 \mathrm{~K}$, which agrees with our experimental findings and the literature on the thermal spark.

\section{Introduction}

Nanosecond Repetitively Pulsed (NRP) discharges are known for being out of equilibrium in preheated air at atmospheric pressure [1]. At ambient pressure, Pai et al. identified three regimes of NRP discharges: the corona, the glow, and the spark. The simulations of these three regimes have already been performed [2-6] based on the kinetic mechanisms of Kossyi et al. [7] or Capitelli et al. [8] which are well-suited for simulations of non-equilibrium plasmas.

However, another regime does not fall in the classification of Pai et al.: the thermal spark. At near atmospheric pressures, the thermal spark has been the subject of several studies in recent years. For instance, Lo et al. applied a 35$\mathrm{kV}$ single nanosecond discharge in a 3-mm gap $(450 \mathrm{Td})$ and measured a sudden increase of gas temperature from 1200 to $35,000 \mathrm{~K}$ in less than $5 \mathrm{~ns}$ [9]. This heating was associated with the emission of $\mathrm{N}^{+}$lines. The electron number density, measured by Stark broadening of $\mathrm{N}^{+}$, reached $n_{e}=9 \times 10^{18} \mathrm{~cm}^{-3}$, representing an ionization of $36 \%$. Such high electron number densities and temperatures were also measured by other teams in pin-to-pin configurations [10-14] and nanosecond Dielectric Barrier Discharges [15,16].

In a previous work [13], we compared our results to the literature and demonstrated that, in pin-to-pin configurations, thermal sparks are generated in five stages:

1. Formation of a partially ionized plasma across the inter-electrodes gap.

2. Formation of a fully ionized filament at the cathode in less than $0.5 \mathrm{~ns}$.

3. Formation of a similar filament at the anode, delayed compared to the cathode filament.

4. Propagation of these two fully ionized filaments toward each other's.

5. Merging of these filaments. The thermal spark is formed.

The fully ionized filaments were found to be at thermal and chemical equilibrium. Although the thermal spark formation was characterized, the reasons behind the abrupt formation of the filaments remained unclear.

In this paper, we investigate the formation of a thermal spark generated in a pin-to-pin configuration. First, in Section II, we describe our experimental setup and, in Section III, we measure the increase of the electron number

\footnotetext{
* Ph.D. Candidate, EM2C, CNRS, CentraleSupélec, Université Paris-Saclay, AIAA Member

${ }^{\dagger}$ Ph.D. Candidate, EM2C, CNRS, CentraleSupélec, Université Paris-Saclay

* Professor, EM2C, CNRS, CentraleSupélec, Université Paris-Saclay

$\S$ Professor, EM2C, CNRS, CentraleSupélec, Université Paris-Saclay, AIAA Fellow
} 
density of the thermal spark. Then, in Section IV, we briefly describe a kinetic mechanism developed in this work and, in Section V, we compare the results of simulations and measurements.

\section{Experimental setup}

The experimental setup, presented in Figure 1, is extensively described in our previous study [13]. Briefly, a nanosecond discharge is generated (FID FPG 30-100MC4K) at $1 \mathrm{kHz}$ between two pin electrodes separated by $1.2 \mathrm{~mm}$. The experiments are performed in ambient air at 1 bar. In specific experiments, we monitor the $\mathrm{H}_{\alpha}$ Stark broadening in a mixture composed of ambient air and $\mathrm{H}_{2}(3.7 \%)$. An Optical Emission Spectroscopy (OES) setup is used to measure the electron number densities and the electron temperatures. The discharge is placed at the focal point of an off-axis parabolic mirror $(f=10 \mathrm{~cm})$, as shown in Figure 1. The collimated light from the plasma is then refocused by a second parabolic mirror $(f=20 \mathrm{~cm}$ ) onto the monochromator (Acton 500i) entrance slit. The monochromator is equipped with two gratings of 300 and $1800 \mathrm{gr} \cdot \mathrm{mm}^{-1}$, both blazed at $500 \mathrm{~nm}$. An ICCD camera (Pi-MAX4) coupled to the monochromator is used to record the spectra with a minimum gate of $450 \mathrm{ps}$. The pitch of the pixels on the ICCD is $13 \mu \mathrm{m}$. A HeNe laser (Thorlabs) is used to determine the instrumental broadening of the OES system.

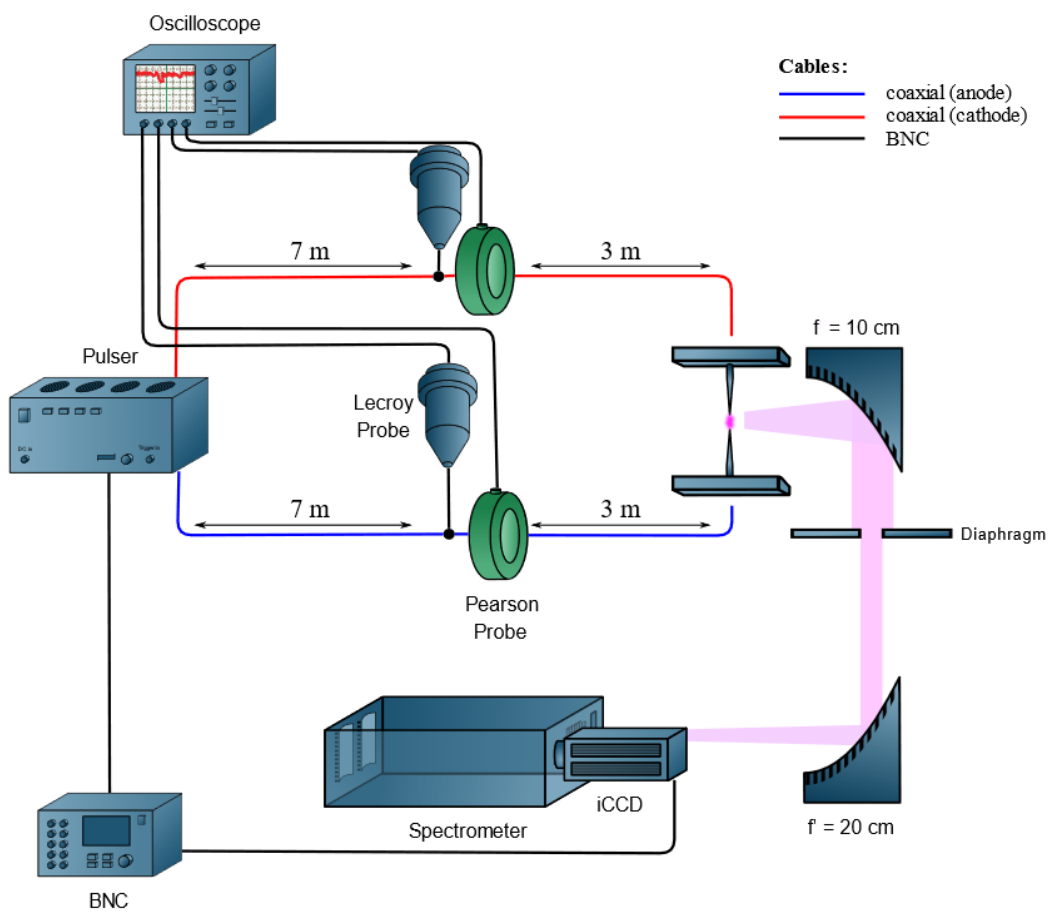

Figure 1 Experimental setup. The length of the coaxial cables is different from previous work [13].

The discharge is generated by a positive 10-ns pulse (sent to the anode) and a negative 10-ns pulse (sent to the cathode). Hence, the energy deposition is monitored by two high voltage probes (LeCroy PPE20kV) and two current transformers (Pearson 6585) connected to an oscilloscope (Lecroy HDO 6104). The measured voltage and current are represented in Figure 2. Note the difference in amplitude between the incident pulses at the anode and at the cathode is only due to a technical peculiarity of the pulser. 

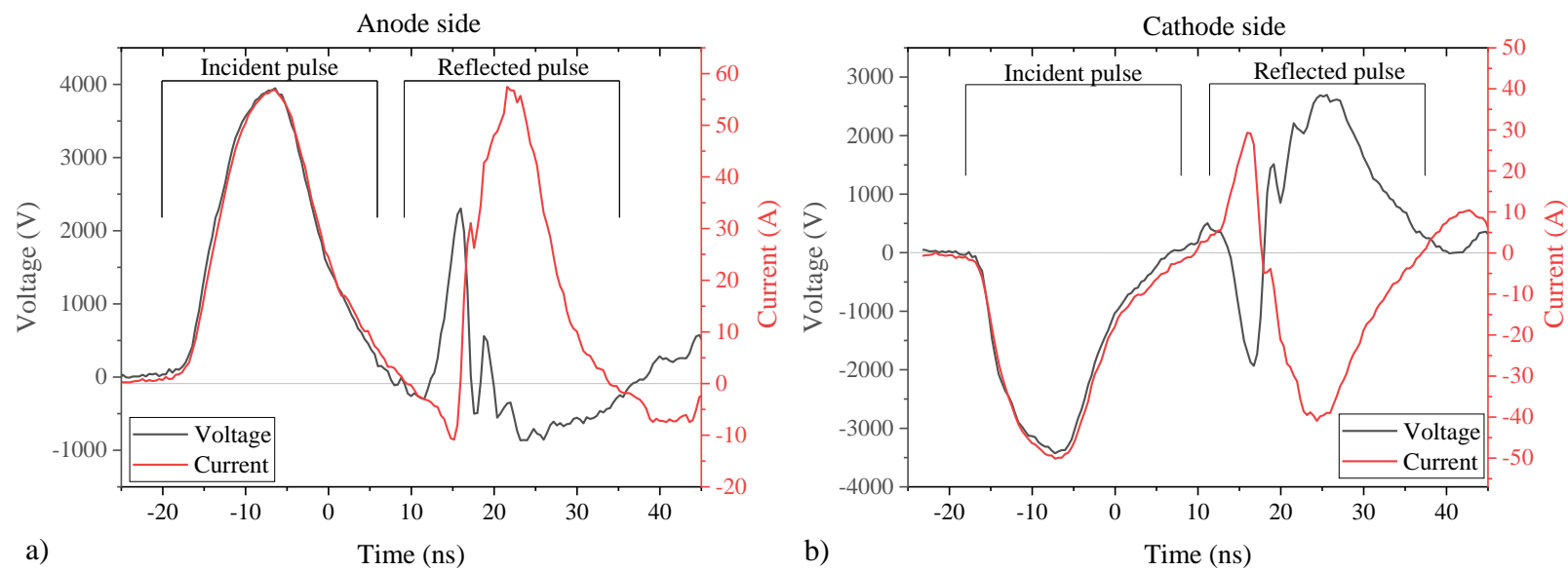

Figure 2 Measured voltage and current on a) the anode and b) the cathode sides.

The instantaneous power is the product of the voltage, $U$, and current, $I$. The total energy, $E$, is the time integration of the power in Eq. 1, where the indices 'an' and 'cat' denote the anode and the cathode, respectively.

$$
E(t)=E_{c a t}(t)+E_{a n}(t)=\int_{0}^{t} I_{c a t}(t) U_{c a t}(t) d t+\int_{0}^{t} I_{a n}(t) U_{a n}(t) d t
$$

Eq. 1

The instant $t=0 \mathrm{~ns}$ is defined as the moment the nanosecond pulse reaches the electrode, after consideration of the propagation time in the coaxial cable. As shown in Figure 3, the incident anode and cathode pulses carry $3.9 \mathrm{~mJ}$ to the interelectrode gap. Due to impedance mismatch between the coaxial cable and the plasma, a part of the energy (1.5 mJ) is reflected to the generator, defined as the upstream direction. Another impedance mismatch on the generator (on OFF position at $t>10 \mathrm{~ns}$ ) leads to a new reflection. Thus, a $2^{\text {nd }}$ pulse is sent in the downstream direction and is detected at $t=75 \mathrm{~ns}$. The second pulse carries $\sim 0.8 \mathrm{~mJ}$ and deposits $\sim 0.25 \mathrm{~mJ}$ in the interelectrode gap. For the same reasons, a $3^{\text {rd }}$ pulse is detected at $t=150 \mathrm{~ns}$ and deposits another $0.25 \mathrm{~mJ}$. This sequential energy deposition was already observed in previous work $[13,17,18]$ and could explain the "ringing" observed in Ref. [19]. In the following, we study the electron number density increase for $t<20 \mathrm{~ns}$. 


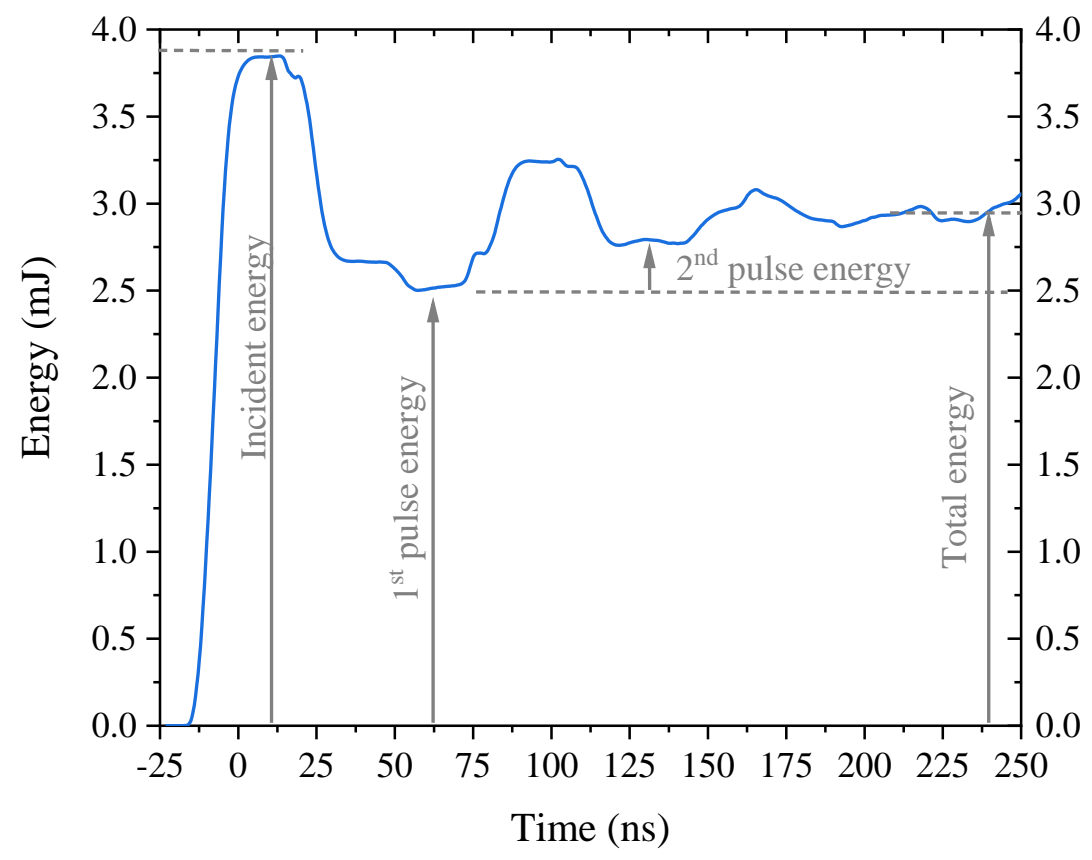

Figure 3 Total transmitted energy according to Eq. 1. Approximately $2.5,0.25$, and $0.25 \mathrm{~mJ}$ are deposited in the $1^{\text {st }}, 2^{\text {nd }}$, and $3^{\text {rd }}$ pulses, respectively.

Table 1 Summary of the experimental parameters of this work, compared to those of a previous study [13].

\begin{tabular}{llll}
\hline & Setup \#1 in [13] & Setup \#2 in [13] & This work \\
\hline Electrode polarities & Cathode-Anode & Cathode-Ground & Cathode-Anode \\
Interelectrode gap & $0.9 \mathrm{~mm}$ & $2 \mathrm{~mm}$ & $1.2 \mathrm{~mm}$ \\
Repetition frequency & $10 \mathrm{~Hz}$ (single pulse) & $10 \mathrm{~Hz}$ (single pulse) & $1 \mathrm{kHz}$ \\
Deposited energy & $2.5-3.5 \mathrm{~mJ}$ per pulse & $2.5 \mathrm{~mJ}$ per pulse & $2.5 \mathrm{~mJ}(0-20 \mathrm{~ns})$ \\
& & & $3.0 \mathrm{~mJ}(0-100 \mathrm{~ns})$ \\
Maximal $\Delta \mathrm{V}$ & $8.5 \mathrm{kV}$ & $5.5 \mathrm{kV}$ & $8 \mathrm{kV}$ \\
Pressure & $58 \mathrm{mbar}-1 \mathrm{bar}$ & $1 \mathrm{bar}$ & $1 \mathrm{bar}$ \\
Gas & Ambient air & Ambient air & Ambient air \\
& & $+1.6 \%$ of $\mathrm{H}_{2}$ & $\left(+3.7 \%\right.$ of $\left.\mathrm{H}_{2}\right)$ \\
\hline
\end{tabular}

We summarized in Table 1 the experimental parameters used in the present study. For comparison, the experimental parameters of our previous work, performed in a single pulse regime, are also shown.

\section{Measurement of the electron number density}

In this section, we measure the ion and electron number density using four methods:

1. Stark broadening of $\mathrm{H}_{\alpha}$, in Section III.A

2. Stark broadening of $\mathrm{N}^{+}$, in Section III.B

3. Calibrated line intensity of $\mathrm{N}^{+}$and $\mathrm{O}^{+}$, in Section III.B

4. Continuum emission of electrons, in Section III.C

The measurements are spatially resolved, but only the results obtained near the cathode are presented in this paper. 


\section{A. Stark broadening of $\mathbf{H}_{\alpha}$}

The electron number density can be accurately measured using the Stark broadening of the $\mathrm{H}_{\alpha}$ line at $656 \mathrm{~nm}$. The Half-Width at Half Maximum (HWHM) of $\mathrm{H}_{\alpha}$ is the sum of several broadening mechanisms: Doppler, resonant, natural, Van der Waals, Stark, and instrumental. In the following, we estimate the non-Stark contributions to the HWHM of the $\mathrm{H}_{\alpha}$ line, and show they are negligible. The broadening formulas used in the present work were initially developed by Griem [20] and simplified for $\mathrm{H}_{\beta}$ in Ref. [21]. The work of Ref. [21] was recently improved and extended to $\mathrm{H}_{\alpha}, \mathrm{H}_{\beta}, \mathrm{O}, \mathrm{N}, \mathrm{O}^{+}, \mathrm{N}^{+}$in Ref. [13].

In the following, we assume that the gas transformation is isochoric up to $t=20 \mathrm{~ns}$ and take the ambient number density, $2.7 \times 10^{19} \mathrm{~cm}^{-3}$, for initial conditions. The gas temperature varies from $300 \mathrm{~K}$ (initial condition) to $\sim 30,000 \mathrm{~K}$ (fully ionized plasma). Based on the gas temperature and number density, we estimate the Doppler, resonant, and Van der Waals HWHM in Table 2 [13]. They are negligible compared to the Stark broadening measurements.

Table 2 Estimation of the $\mathrm{H}_{\alpha}$ line HWHM (in pm) for the present conditions based on the formula given in Ref. [13]. See also Table 3 for the estimation of the Van der Waals HWHM.

\begin{tabular}{ccccccc}
\hline $\begin{array}{c}\text { Time } \\
(\mathrm{ns})\end{array}$ & $\begin{array}{c}\mathrm{T}_{\mathrm{gas}} \\
(\mathrm{K})\end{array}$ & $\begin{array}{c}\text { Doppler } \\
(\mathrm{pm})\end{array}$ & $\begin{array}{c}\text { Resonant } \\
(\mathrm{pm})\end{array}$ & $\begin{array}{c}\text { Van der Waals } \\
(\mathrm{pm})\end{array}$ & $\begin{array}{c}\text { Instrumental broadening } \\
(\mathrm{pm})\end{array}$ & $\begin{array}{c}\text { Stark } \\
(\mathrm{pm})\end{array}$ \\
\hline $0-4$ & $300-3000$ & $4-12$ & $<1$ & $<34$ & $\begin{array}{c}48 \\
\left(1800 \mathrm{gr} \cdot \mathrm{mm}^{-1}\right)\end{array}$ & $\begin{array}{c}342 \\
\left(300 \mathrm{gr} \cdot \mathrm{mm}^{-1}\right)\end{array}$ \\
$3-20$ & $3000-30,000$ & $12-38$ & $<1$ & $<267$ & $600-600-23,000$ \\
\hline
\end{tabular}

The Doppler HWHM increases with the square root of the gas temperature. Thus, the Doppler width will be considered constant. The number density of atomic hydrogen is estimated to be below $10^{15} \mathrm{~cm}^{-3}$, resulting in a negligible resonant broadening $(\mathrm{HWHM}<1 \mathrm{pm})$. The natural broadening is also negligible.

The Van der Waals HWHM results from the perturbation of the $\mathrm{H}_{\alpha}$ transition by non-hydrogenic particles $\left(\mathrm{N}_{2}, \mathrm{O}_{2}, \mathrm{O}\right.$, $\mathrm{N}, \mathrm{O}^{+}$, and $\mathrm{N}^{+}$). The sum over all the contributions is given in Eq. 2, where $N$ is the total gas density, $T_{\text {gas }}$ the gas temperature, and $x_{\text {pert }}$ the perturber mole fraction. The coefficients $\gamma_{\text {pert }}$ are specific to each couple transition - perturber and are calculated in Ref. [13].

$$
\Delta \lambda_{\text {Van der Waals }}[\mathrm{nm}]=\frac{N}{2.7 \times 10^{19} \mathrm{~cm}^{-3}}\left(\frac{T_{\text {gas }}}{273 \mathrm{~K}}\right)^{0.3} \sum_{\text {pert }}\left(\frac{\gamma_{\text {pert }}}{100} x_{\text {pert }}\right) \quad \text { Eq. } 2
$$

We simplify the sum in Eq. 2 using $\gamma_{\text {mean }}$ defined in Eq. 3.

$$
\gamma_{\text {mean }}=\sum_{\text {pert }}\left(x_{\text {pert }} \gamma_{\text {pert }}\right)
$$

In Table 3, the value of $\gamma_{\text {mean }}$ is calculated in air. During the thermal spark formation, the gas composition varies from $\mathrm{N}_{2} / \mathrm{O}_{2}$ at $300 \mathrm{~K}$, to N / O at 20,000 K and finally $\mathrm{N}^{+} / \mathrm{O}^{+}$at 40,000 K. For these compositions, the Van der Waals HWHM varies from 34 to $267 \mathrm{pm}$. For comparison, when the plasma is partially ionized, a Stark HWHM of $34 \mathrm{pm}$ corresponds to $n_{e} \sim 10^{14} \mathrm{~cm}^{-3}$, which is well below our sensitivity limit. When the gas is fully ionized and $T=40,000 \mathrm{~K}$, a Stark HWHM of $267 \mathrm{pm}$ corresponds to $3 \times 10^{16} \mathrm{~cm}^{-3}$, which is three orders of magnitude lower than the measured electron number density.

Table 3 Estimated $\gamma_{\text {mean }}$ coefficient and Van der Waals broadening HWHM of the $\mathrm{H}_{\alpha}$ line in ambient air at $300 \mathrm{~K}$, dissociated air at $20,000 \mathrm{~K}$, and fully ionized air at $40,000 \mathrm{~K}$.

\begin{tabular}{lcccc}
\hline Composition & $\gamma_{\text {mean }}$ & $T(\mathrm{~K})$ & $N\left(\mathrm{~cm}^{-3}\right)$ & $\Delta \lambda_{V d W}(\mathrm{HWHM}-\mathrm{pm})$ \\
\hline $\mathrm{N}_{2} / \mathrm{O}_{2}$ & 3.36 & 300 & $2.7 \times 10^{19}$ & 34 \\
$\mathrm{~N} / \mathrm{O}$ & 3.64 & 20,000 & $5.4 \times 10^{19}$ & 150 \\
$\mathrm{~N}^{+} / \mathrm{O}^{+}$ & 3.26 & 40,000 & $5.4 \times 10^{19}$ & 267 \\
\hline
\end{tabular}


The Stark HWHM can be calculated"* with Eq. 4 [22,23].

$$
\frac{n_{e}}{10^{17} \mathrm{~cm}^{-3}}=\left(\frac{\Delta \lambda_{\text {Stark }, \mathrm{H} \alpha}}{0.549 \mathrm{~nm}}\right)^{1.47134}
$$

The instrumental broadening mainly depends on the spectrometer slit opening and the grating. We used two gratings in this study to follow the variations of the $\mathrm{H}_{\alpha} \mathrm{HWHM}$ from $0.1 \mathrm{~nm}$ to $20 \mathrm{~nm}$. The corresponding instrumental HWHM is given in Table 2. A typical example of the $\mathrm{H}_{\alpha}$ line fitting is shown in Figure 4. The $\mathrm{H}_{\alpha}$ width uncertainty is about $\pm 20 \%$, which leads to a $30 \%$ uncertainty on the $n_{e}$ measurement with this technique.

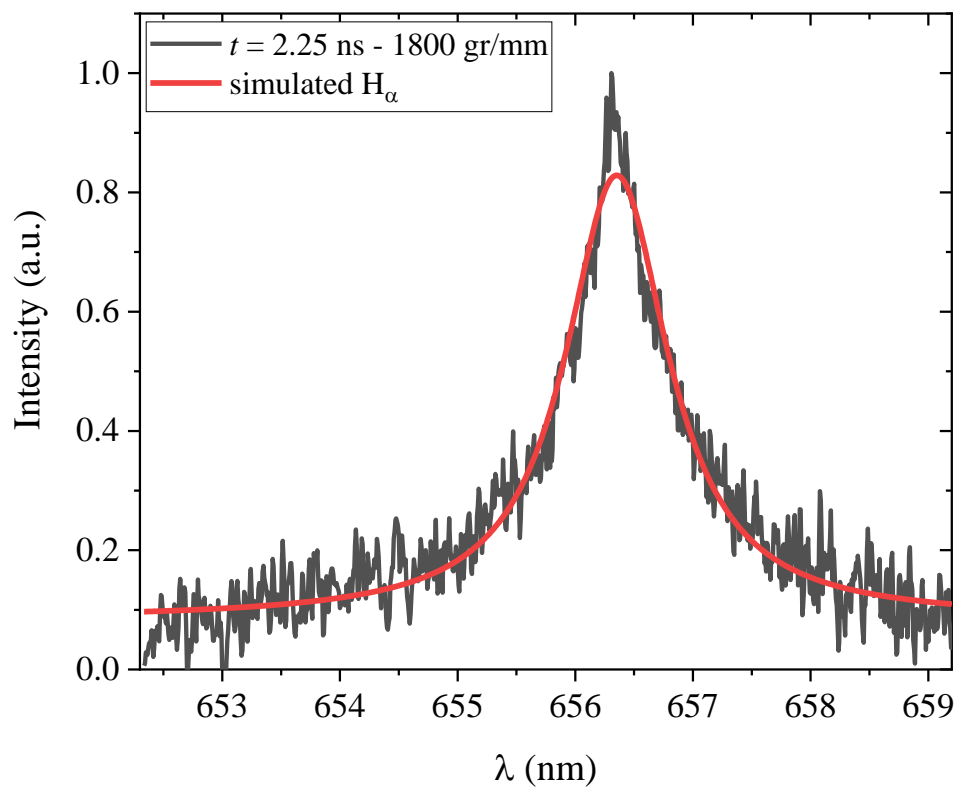

Figure 4 Fitting of the $H_{\alpha}$ line at $t=2.25 \mathrm{~ns}(1800-\mathrm{gr} / \mathrm{mm}$ grating $)$.

In this work, some of the Stark broadening measurements are performed during the high-voltage pulse. In Ref. [24], it was shown that the applied electric field can have an impact on the Stark broadening. In that case, the width of the spectral line would be related to the current density instead of the electron number density. In Ref. [24], expressions are derived for the Stark broadening of $\mathrm{H}_{\alpha}$ and $\mathrm{H}_{\beta}$ generated by the sum of two fields:

- A microscopic field, arising from the presence of ions and electrons in the plasma. This is the typical Stark broadening effect.

- A macroscopic field applied in one direction during the experiment. This field can interfere with the Stark broadening.

According to Bastien \& Marode, the $\mathrm{H}_{\beta}$ Stark broadening is mainly due to the shifting of intense external lines caused by the static ions' microfield [24]. The addition of an external field has, therefore, an impact on the $\mathrm{H}_{\beta}$ Stark broadening. On the other hand, Bastien \& Marode showed that the addition of an external field has a weak impact on the $\mathrm{H}_{\alpha}$ lineshape. For instance, at $n_{e}=10^{17} \mathrm{~cm}^{-3}$ and $T_{e}=10,000 \mathrm{~K}$, the Stark HWHM of $\mathrm{H}_{\alpha}$ remains independent of the applied field up to at least ${ }^{\dagger \dagger} 12 \mathrm{kV} \cdot \mathrm{mm}^{-1}$, see Table 1 of [24]. In our experiments, the maximum applied field is $6.7 \mathrm{kV} \cdot \mathrm{mm}^{-1}$

*** The relation given initially by Gigosos et al. [22] must be corrected by a factor 2 as noted by Konjević et al. [23].

${ }^{\dagger}$ Bastien \& Marode calculated the effect of the external field up to four times the Holtsmark field, where the Holtsmark field is, in SI unit:

$$
E_{\text {Holzmark }}=\frac{e}{4 \pi \varepsilon_{0} n_{e}^{2 / 3}}
$$

where $e$ is the elementary charge, $\varepsilon_{0}$ the dielectric constant, and $n_{e}$ the electron number density. 
when $n_{e} \sim 10^{17} \mathrm{~cm}^{-3}$. Therefore, the applied field does not influence our Stark broadening measurements of $\mathrm{H}_{\alpha}$ during the pulse.

\section{B. Stark broadening and intensity of the $\mathrm{N}^{+}$lines}

We expect that the plasma will reach full ionization and hence thermal and chemical equilibrium at $T=30,000 \mathrm{~K}-$ $50,000 \mathrm{~K}$ [13]. At these temperatures, after an isochoric transformation, the plasma is mainly composed of electrons $(50 \%), \mathrm{N}^{+}(40 \%)$ and $\mathrm{O}^{+}(10 \%)$ [25]. Thus, the number density of the ions $\left(\mathrm{N}^{+}\right.$and $\left.\mathrm{O}^{+}\right)$is expected to follow $n_{e}$. We measure the densities of several excited states of the ions by calibrated OES and infer the total ion density assuming a Boltzmann distribution of the electronic states at the measured electron temperature. The OES calibration is performed using an integration lamp (OL455, Gooch and Housego).

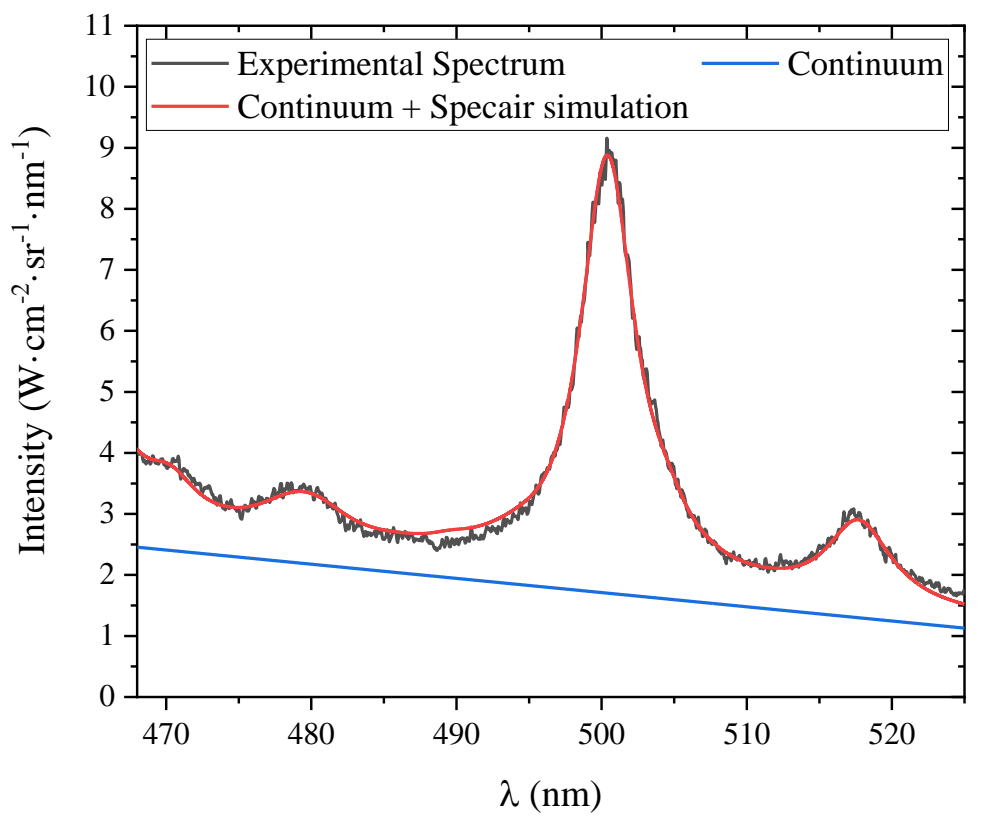

Figure 5 Fit of the $\mathrm{N}^{+}$and $\mathrm{O}^{+}$emission near the cathode at $t=9.75 \mathrm{~ns}$. The continuum emission is approximated by a linear function (in blue) and the $\mathrm{N}^{+}$and $\mathrm{O}^{+}$emission is calculated by Specair (in red). The $\mathrm{N}^{+}$and $\mathrm{O}^{+}$lines are calculated accounting for self-absorption $(\Delta l=15 \mu \mathrm{m})$. The fit gives $n_{e}=2.0 \times 10^{19} \mathrm{~cm}^{-3}, n_{N_{+}}=3.6 \times 10^{18} \mathrm{~cm}^{-3}, n o_{+}=1.2 \times 10^{17} \mathrm{~cm}^{-3}$, and $T_{e}=35,000 \mathrm{~K}$ (accuracy discussed in the text).

A typical spectrum, shown in Figure 5, is fitted with a Specair calculation [21,26]. For $\mathrm{N}^{+}$lines, the Stark line broadening dominates the others and the lineshape fit provides another measurement of $n_{e}$. The uncertainty on the Stark broadening fitting (and $n_{e}$ determination) remains below 20\%. The continuum radiation (assumed to be linear) is subtracted and studied in Section III.C. All electronic states of the ions are assumed to follow a Boltzmann distribution at $T_{e}$. The measured electronic temperature $\left(T_{e}=35,000 \mathrm{~K}\right)$ corresponds to values usually reported in thermal spark literature $[9,12,13]$. In the following, we discuss the determination of $\mathrm{N}^{+}$and $\mathrm{O}^{+}$number density.

In the work of Shcherbanev et al. [16], it was reported that the emission of filamentary SDBD was indeed the sum of two concentric channels. In their case, the intense $\mathrm{N}^{+}$and continuum emissions were emitted from the central core, whereas a weaker $\mathrm{N}_{2}$ emission originated from the outer shell. Shcherbanev et al. reported a filament Full Width at Half Maximum (FWHM) of $18 \pm 2 \mu \mathrm{m}$. In a configuration similar to ours, Orriere measured the FWHM of a thermal spark [27]. He found an FWHM of $50 \mu \mathrm{m}$ for a $6-\mathrm{kV}$ discharge of $20 \mathrm{~ns}$ applied across a 1-mm gap between the electrodes $\$$. However, no filter was used and the measurement of Orriere et al. is an upper bound of their thermal

$\$$ For a 2-kV pulse across 200- $\mu \mathrm{m}$ gap, Orriere measured a FWHM of $40 \mu \mathrm{m}$. 
spark diameter. Finally, in a $25-\mathrm{kV}$ discharge of $40 \mathrm{~ns}$ at ambient conditions, Parkevich et al. measured the $n_{e}$ distribution of a thermal spark by interferometry [14]. Their discharge looked homogeneous with conventional lenses but was indeed composed of several fully ionized filaments, $10-50 \mu \mathrm{m}$ in diameter. Finally, Lo et al. clearly observed a constriction of the discharge channel during the transition to the thermal spark in a microsecond pulsed discharge in air [9].

In the present study, the plasma column diameter is estimated with a 10-nm bandpass filter centered at $480 \mathrm{~nm}$ (Hard Coated OD 4.0 10-nm Bandpass Filter, Edmund Optics). An accurate measurement is challenging with our present setup because of shot-to-shot fluctuations (of the order of a few 10s of microns) and because the column width is comparable with the pixel width, which could result in pixel bleeding. Based on these measurements, we assume in the following that the plasma diameter is constant in time and of the order or less than the pixel resolution, i.e. $\Delta l=15 \mu \mathrm{m}$. We note that this value is comparable with the measurements of Shcherbanev et al., Orriere, and Parkevich et al.

The accuracy of the $T_{e}$ measurements is $\pm 10 \%$. This uncertainty has strong consequences on the number density of the ions. For instance, in Figure 6, we show three $\mathrm{N}^{+}$spectra calculated at 35,000 $\mathrm{K} \pm 10 \%$. The $\mathrm{N}^{+}$number density of each spectrum in Figure 6 is adjusted to conserve the peak intensity at $\lambda=500 \mathrm{~nm}$. This example shows that a $10 \%$ variation on $T_{e}$ results in a factor-two increase/decrease in the $\mathrm{N}^{+}$number density.

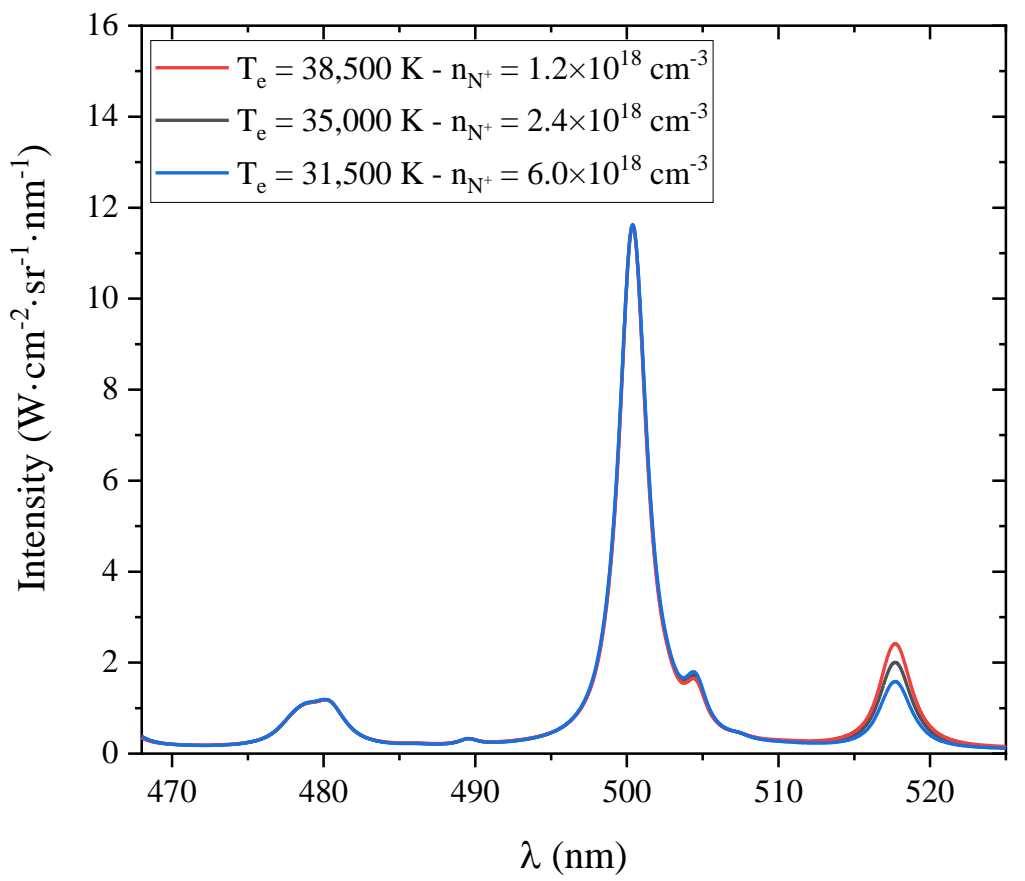

Figure 6 Influence of the temperature on the $\mathrm{N}^{+}$number density. Three spectra are calculated using Specair [21,26] at $35,000 \mathrm{~K} \pm 10 \%$, accounting for the slight self-absorption in a $40-\mu \mathrm{m}$ plasma column.

Note that the Stark broadening constants of the lines at $518 \mathrm{~nm}$ are not available in the literature above $28,000 \mathrm{~K}$. Their values were adjusted in previous work, see the appendix in Ref. [13], and are consistent with the values found at lower temperatures in the literature, but could add uncertainty to the measurement. Thus, we estimate that the statistical error on the measurements of $\mathrm{N}^{+}$and $\mathrm{O}^{+}$number densities is about a factor of two. The impact of the plasma diameter estimation is discussed in Section III.D. Nevertheless, we conclude that the positive ion $\left(\mathrm{N}^{+}\right.$and $\left.\mathrm{O}^{+}\right)$number density is in the range $10^{18}-10^{19} \mathrm{~cm}^{-3}$, which is consistent with the maximal electron number density measured by Stark broadening $\left(\sim 10^{19} \mathrm{~cm}^{-3}\right)$. 


\section{Continuum radiation of electrons}

As shown in several works, continuum radiation can be significant in laser-induced plasmas [28], DBD discharges [16], or pin-to-pin nanosecond discharges [10]. We decompose the plasma volumetric emission coefficient, $\varepsilon$, in two terms: the bound-bound emission coefficient, $\varepsilon_{b b}$, and the continuum emission coefficient, $\varepsilon_{c}$.

$$
\varepsilon=\varepsilon_{b b}+\varepsilon_{c}
$$

The bound-bound contribution was discussed in the previous section. The continuum emission is the sum of the freefree radiation (also called Bremsstrahlung) and the free-bound radiation (also called recombination continuum). The continuum emission coefficient is given in Eq. 6, where $n_{e}$ and $n_{i}$ are the electron and ion number densities, $Z_{i}$ the ion charge, $T_{e}$ the electron temperature, $\xi$ the free-bound Gaunt factor, and $G$ the free-free Gaunt factor [29].

$$
\varepsilon_{c}\left(\lambda, T_{e}, n_{e}\right)=C_{8} Z_{i} \frac{n_{e} n_{i}}{\lambda^{2} \sqrt{T_{e}}}\left[\xi\left(1-e^{-u}\right)+G e^{-u}\right]
$$

If more than one ion is present in the mixture, the total continuum radiation will be a sum over $Z_{i}, i$ being the ion species. In the present case, we consider that $\mathrm{N}^{+}$is the dominant ion and $Z_{i}=1$. If the plasma is mainly composed of neutral atoms, another formulation must be used, see Refs. [30,31]. The $C_{8}$ constant can be determined with Eq. 7 , where $e$ is the electron charge, $k_{b}$ the Boltzmann constant, $c$ the speed of light, and $m_{e}$ the electron mass.

$$
C_{8}=\frac{16 \pi e^{6}}{3 c^{2} \sqrt{6 \pi m_{e}^{3} k_{b}}}=1.63 \times 10^{-34}\left[\mathrm{~W} \cdot \mathrm{m}^{3} \cdot \mathrm{nm} \cdot \mathrm{K}^{0.5} \cdot \mathrm{sr}^{-1}\right]
$$

The dimensionless variable $u$ is defined in Eq. 8, where $h$ is the Planck constant, $k_{b}$ the Boltzmann constant, $c$ the speed of light and $\lambda$ the wavelength.

$$
u=\frac{h c}{\lambda k_{b} T_{e}}
$$

The free-free Gaunt factor of $\mathrm{N}^{+}$(and $\mathrm{O}^{+}$) at $\lambda=500 \mathrm{~nm}$ varies from $G=1.08$ to $G=1.1$ for $T$ in the range $32,000-$ $42,000 \mathrm{~K}$, interpolating ${ }^{\S}$ the results of Ref. [32]. The free-bound Gaunt factor should be averaged on the atom's final states (i.e. after the electron has recombined with the ion). The free-bound gaunt factor at $\lambda=500 \mathrm{~nm}=0.18 \mathrm{Ry}$ ranges between $\xi=0.8$ and $\xi=1.2$ depending on the final bound state, see the values calculated for any ions in Table 1 of Ref. [33]. Therefore, we assume $\xi=1$ and $G=1.09$ in the present application. These coefficients are assumed to be accurate $^{* * *}$ within $10 \%$.

Assuming $n_{e}=n_{i}$, we obtain $n_{e}\left[\mathrm{~m}^{-3}\right]$ as a function of $\lambda[\mathrm{nm}]$, the volumetric emission coefficient $\varepsilon_{c}\left[\mathrm{~W} \cdot \mathrm{m}^{-3} \cdot \mathrm{sr}^{-1} \cdot \mathrm{nm}^{-1}\right]$, and $T_{e}[\mathrm{~K}]$, see Ref. [29]:

$$
n_{e}^{2}=\frac{\lambda^{2} \sqrt{T_{e}}}{C_{8}} \frac{1}{\xi\left(1-e^{-u}\right)+G e^{-u}} \varepsilon_{c}
$$

We can relate $\varepsilon_{c}$ with the continuum intensity $I_{c}\left[\mathrm{~W} \cdot \mathrm{m}^{-2} \cdot \mathrm{sr}^{-1} \cdot \mathrm{nm}^{-1}\right]$, the absorption coefficient $k$ [m $\left.{ }^{-1}\right]$, and the plasma width $\Delta l[\mathrm{~m}]$.

\footnotetext{
$\S \S$ We used the ChiantiPy Python package [48,49] at https://github.com/chianti-atomic/ChiantiPy.

*** If needed, a more precise value could be obtained using the summation performed by the ChiantiPy Python Package with the values of Ref. [50]. As described later, the dominant uncertainty is on the plasma thickness.
} 


$$
I_{c}=\varepsilon_{c} \frac{1-\exp (-k \Delta l)}{k}
$$

As in Eq. 5, the absorption coefficient, $k$, is the sum of the continuum and bound-bound absorption, $k_{b b}$ and $k_{c}$, respectively. We assume that the absorption coefficient is dominated by the bound-bound contribution, i.e. $k \sim k_{b b}$. For a plasma diameter of $15 \mu \mathrm{m}$ and $n_{e}=n_{N^{+}}=10^{19} \mathrm{~cm}^{-3}$, we calculated with Specair that $k_{b b} \Delta l<0.5$ between 460 and $530 \mathrm{~nm}$. Based on this estimation, the plasma is optically thin, i.e. $I_{c} \approx \varepsilon_{c} \Delta l$. This approximation leads to, at most, an overestimation of $\varepsilon_{c}$ by $40 \%$. We will see in the next paragraph that this uncertainty is acceptable. Finally, Eq. 9 can be further simplified as Eq. 11 where $n_{e}\left[\mathrm{~m}^{-3}\right]$ is given as a function of $\Delta l[\mathrm{~m}]$ the plasma width, $I_{c}\left[\mathrm{~W} \cdot \mathrm{m}^{-2} \cdot \mathrm{sr}^{-1} \cdot \mathrm{nm}^{-1}\right]$ the continuum intensity, $T_{e}[\mathrm{~K}]$ the electron temperature, and $\lambda[\mathrm{nm}]$ the wavelength of observation.

$$
n_{e}=\left(\frac{\lambda^{2} \sqrt{T_{e}}}{C_{8}} \frac{1}{\xi\left(1-e^{-u}\right)+G e^{-u}} \frac{I_{c}}{\Delta l}\right)^{\frac{1}{2}}
$$

The uncertainty of this measurement is now discussed. Thanks to the power $1 / 2$ on the right-hand side of Eq. 11, the large uncertainties mentioned earlier will be halved in the final result. The uncertainty on $T_{e}$ is about $10 \%$. The freefree and free-bound coefficients vary slowly with $T_{e}$ and, in this case, are known within $\pm 10 \%$. The intensity calibration of the absolute spectrum was performed with other sources and are found to be accurate within about $\pm 20 \%$. Thus, considering the thin plasma maximal uncertainty, the maximal uncertainty on $\varepsilon_{c}$ is $+20 \%$ and $-60 \%$. The plasma thickness, $\Delta l$, is assumed to be exact and discussed later. We find that the $n_{e}$ measurement by continuum emission is accurate by $-50 \%$ and $+30 \%$ after propagation of uncertainty.

\section{Comparison of the four measurements}

In Figure 7, we compare electron number densities measured with the four different techniques applied in this section. The $\mathrm{H}_{\alpha}$ line measurements are performed using two gratings, with overlap between the acquisitions to ensure reproducibility. From $t=1.25 \mathrm{~ns}$ to $t=8 \mathrm{~ns}, n_{e}$ increases from $10^{16}$ to $3 \times 10^{19} \mathrm{~cm}^{-3}$. Note that the steep increase of the electron number density (more than one decade) at $t=4 \mathrm{~ns}$ corresponds to the filament formation. For $t>10 \mathrm{~ns}$, the electron density slowly decays to $5 \times 10^{18} \mathrm{~cm}^{-3}$ at $25 \mathrm{~ns}$. 


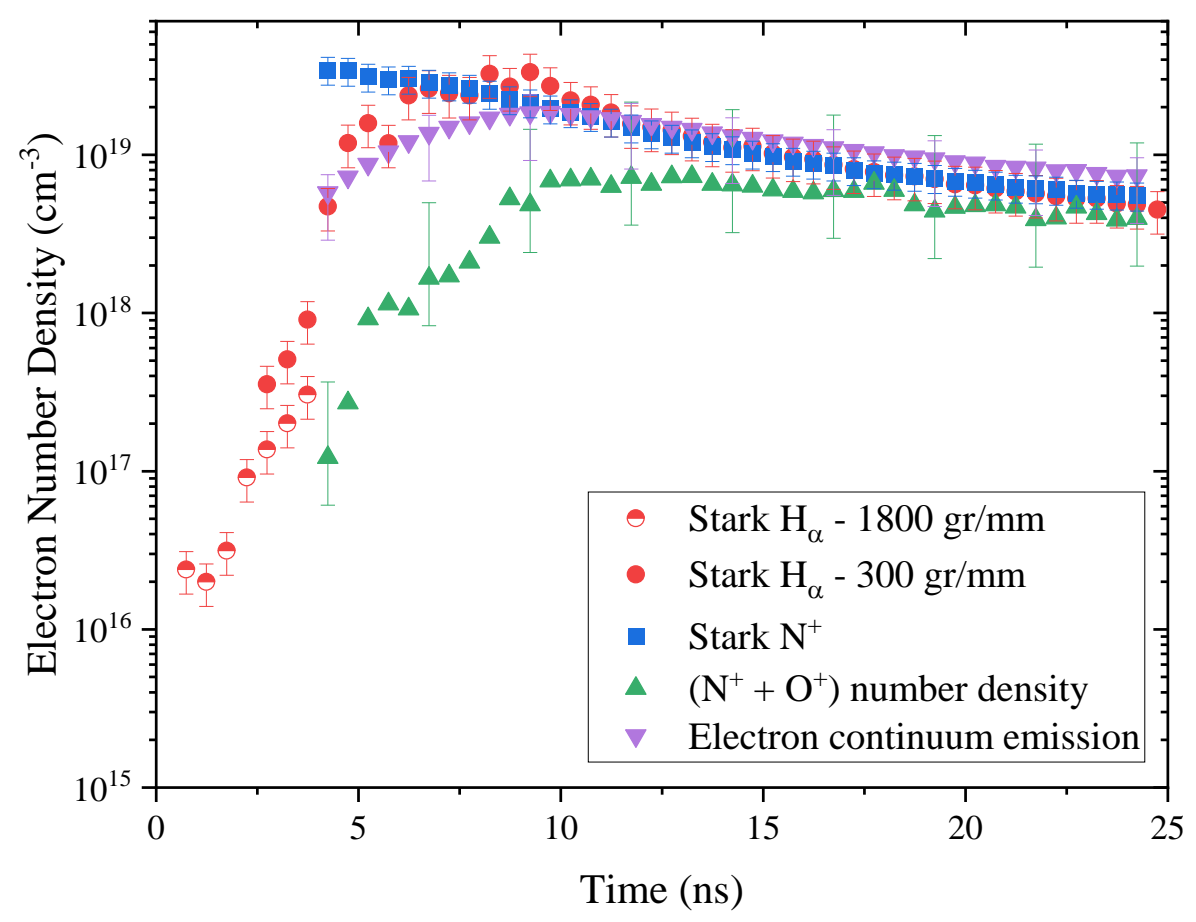

Figure 7 Evolution of the electron number density near the cathode measured with Stark broadening of $\mathrm{H}_{\alpha}$ (red circles), Stark broadening of $\mathrm{N}^{+}$(blue squares), intensity of $\mathrm{N}^{+}$lines (green triangles), and continuum radiation (purple triangles). We assumed an optically thin plasma for continuum radiation only (uncertainty propagated in the error bars). The plasma width is taken to be constant and equal to $15 \mu \mathrm{m}$.

We note that the measurements from the Stark broadening of $\mathrm{H}_{\alpha}$ and $\mathrm{N}^{+}$are in excellent agreement. The electron number densities measured with the continuum emission and the intensity of $\mathrm{N}^{+}$and $\mathrm{O}^{+}$lines agree within the uncertainties of each technique for $t>12 \mathrm{~ns}$. However, at earlier times, the electron densities measured from the absolute OES measurements underestimate the electron number density. This could be because the diameter of the plasma column was overestimated. Since the plasma is neutral, we can use the absolute OES measurements to infer the diameter of the plasma column. To do so, we assume that the ion number density is equal to the electron number density measured by Stark broadening of $\mathrm{N}^{+}$, and we adjust the plasma diameter so that the OES measurements yield the same number density as the Stark broadening measurements. This method enables us to determine the evolution of the plasma diameter as a function of time. The inferred plasma diameter evolution is shown in Figure 8. The same procedure is applied for the continuum radiation measurements, using the electron number density determined from the Stark broadening of $\mathrm{N}^{+}$as a reference. As shown in Figure 8, the two methods provide a plasma diameter evolution that agrees within a factor of about 2 at times greater than $10 \mathrm{~ns}$. This agreement level is actually quite good, considering the uncertainties on each of these two independent, absolute emission-based techniques. These discharge diameters also correspond to those reported by Shcherbanev et al. [16]. 


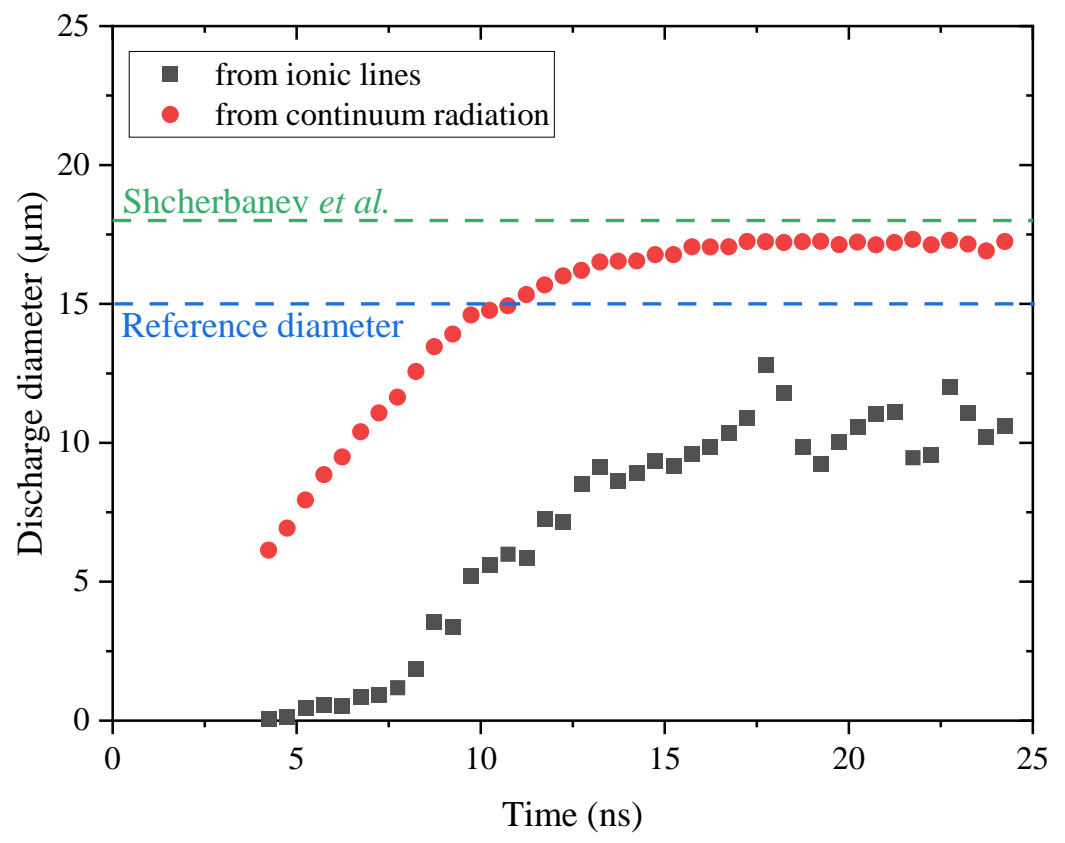

Figure 8 Discharge diameter estimation from the continuum and atomic line radiations. These evolutions are compared to the diameter estimation performed earlier in our conditions (dashed blue line) and the diameter measured in Ref. [16] (dashed green line).

According to the measurement of ionic lines, the measurements obtained with the filtered images overestimated the plasma diameter at all times. According to the continuum radiation, the $15-\mu \mathrm{m}$ diameter was overestimated for $t<10 \mathrm{~ns}$ and underestimated at later times. From the graphical comparison, we conclude that a $15-\mu m$ diameter is ultimately a reasonable approximation.

\section{Kinetic model description}

It has been shown numerically in Ref. [16] that the ionization rate in nanosecond DBD can be increased by the electron impact ionization of $\mathrm{N}_{2}(\mathrm{~B})$ and $\mathrm{N}_{2}(\mathrm{C})$. We demonstrated in Ref. [34,35] that this process has indeed a significant impact, but that the formation of a fully-ionized plasma by a single nanosecond discharge is rather due to the electronimpact ionization of electronically excited states of $\mathrm{N}$ and $\mathrm{O}$. We therefore developed a model of ionization adapted for air discharges, including the ionization of $\mathrm{N}_{2}, \mathrm{~N}$, and $\mathrm{O}$ excited states. The complete reaction set is given in Ref. [36, Chap. 5] and only its major features are described here. The mechanism includes $\mathrm{N}_{2}, \mathrm{O}_{2}, \mathrm{NO}, \mathrm{N}, \mathrm{O}_{2} \mathrm{~N}_{2}^{+}, \mathrm{O}_{2}{ }^{+}, \mathrm{NO}^{+}, \mathrm{N}^{+}$, $\mathrm{O}^{+}, \mathrm{N}^{++}$, and $\mathrm{O}^{++}$. The chemistry of ground states species is based on the reaction set of Laux et al. [37,38]. We added the excitation, ionization, and dissociation by electron impact of four excited states of $\mathrm{N}_{2}: \mathrm{N}_{2}(\mathrm{~A}), \mathrm{N}_{2}(\mathrm{~B}), \mathrm{N}_{2}\left(\mathrm{a}^{\prime}\right)$, and $\mathrm{N}_{2}(\mathrm{C})$ [39].

$$
\begin{gathered}
\mathrm{N}_{2}(Y)+\mathrm{e} \leftrightarrow \mathrm{N}_{2}{ }^{+}+2 \mathrm{e} \\
Y=\mathrm{A}, \mathrm{B}, \mathrm{a}, \mathrm{C}
\end{gathered}
$$

Reac. 1

We also included the dissociation of $\mathrm{O}_{2}$ by $\mathrm{N}_{2}$ excited states quenching [40]. The electron impact ionization of the first three electronic states of $\mathrm{O}$ are also included: $\mathrm{O}\left({ }^{3} \mathrm{P}\right), \mathrm{O}\left({ }^{1} \mathrm{D}\right)$, and $\mathrm{O}\left({ }^{1} \mathrm{~S}\right)[41]$.

$$
\begin{gathered}
\mathrm{O}(Y)+\mathrm{e} \leftrightarrow \mathrm{O}^{+}+2 \mathrm{e} \\
Y={ }^{3} \mathrm{P},{ }^{1} \mathrm{D},{ }^{1} \mathrm{~S}
\end{gathered}
$$

Reac. 2

Concerning $\mathrm{N}$ electronic states, we included the ionization of eight electronic states of $\mathrm{N}: \mathrm{N}\left({ }^{4} \mathrm{~S}^{0}\right), \mathrm{N}\left({ }^{2} \mathrm{D}^{0}\right), \mathrm{N}\left({ }^{2} \mathrm{P}^{0}\right), \mathrm{N}\left({ }^{4} \mathrm{P}\right)$, $\mathrm{N}\left({ }^{2} \mathrm{P}\right), \mathrm{N}\left({ }^{4} \mathrm{P}, 2 \mathrm{~s}^{2} 2 \mathrm{p}^{4}\right), \mathrm{N}\left({ }^{2} \mathrm{~S}^{0}\right)$, and $\mathrm{N}\left({ }^{4} \mathrm{D}^{0}\right)[42,43]$. 


$$
\begin{gathered}
\mathrm{N}(Y)+\mathrm{e} \leftrightarrow \mathrm{N}^{+}+2 \mathrm{e} \\
Y={ }^{4} \mathrm{~S}^{0},{ }^{2} \mathrm{D}^{0},{ }^{2} \mathrm{P}^{0},{ }^{4} \mathrm{P},{ }^{2} \mathrm{P},{ }^{4} \mathrm{P},{ }^{2} \mathrm{~S}^{0},{ }^{4} \mathrm{D}^{0}
\end{gathered}
$$

For a field of up to $240 \mathrm{Td}$ at ambient conditions, we demonstrated that the discharge ionization is essentially due to the ionization of the first six electronic states of $\mathrm{N}$ [34-36]. The 0-D plasma kinetics and the gas energy equation are solved using ZDPlasKin [44]. The Electron Energy Distribution Function (EEDF) is computed using BOLSIG+ $[45,46]$. A simplified representation of the kinetic mechanism is given in Figure 9.

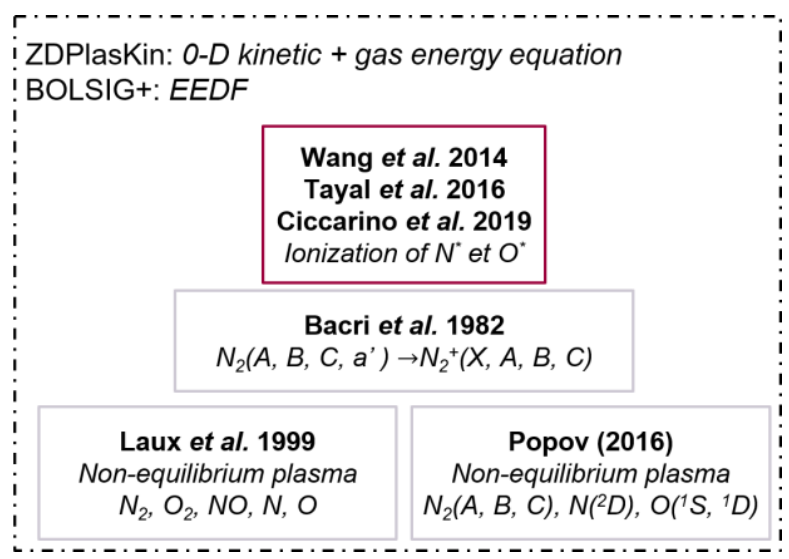

Figure 9 Schematic representation of the reactions included in our mechanism [36] based on the work of Refs. [38-43].

\section{Comparison of the numerical kinetics with the experimental findings}

We now compare the measurements near the cathode and the simulation. Initial conditions and numerical parameters are listed in Table 4.

Table 4 Initial conditions and numerical parameters. The initial $\mathrm{N}_{2}$ and $\mathrm{O}_{2}$ number densities correspond to air at 1 atm and $300 \mathrm{~K}$, and the initial electron and $\mathrm{N}_{2}{ }^{+}$number densities to typical ionization in streamer discharges.

\begin{tabular}{llllllll}
\hline \multicolumn{2}{l}{ Initial gas state } & & & & Numerical parameters \\
\hline $\mathrm{N}_{2}\left(\mathrm{~cm}^{-3}\right)$ & $\mathrm{O}_{2}\left(\mathrm{~cm}^{-3}\right)$ & $\mathrm{N}_{2}{ }^{+}\left(\mathrm{cm}^{-3}\right)$ & $\mathrm{e}-\left(\mathrm{cm}^{-3}\right)$ & $T_{\text {gas }}(\mathrm{K})$ & $T_{e}(\mathrm{~K})$ & & Time step $(\mathrm{ps})$ \\
$1.90 \times 10^{19}$ & $5.06 \times 10^{18}$ & $1.00 \times 10^{14}$ & $1.00 \times 10^{14}$ & 300 & 1000 & & 1.0 \\
\hline
\end{tabular}




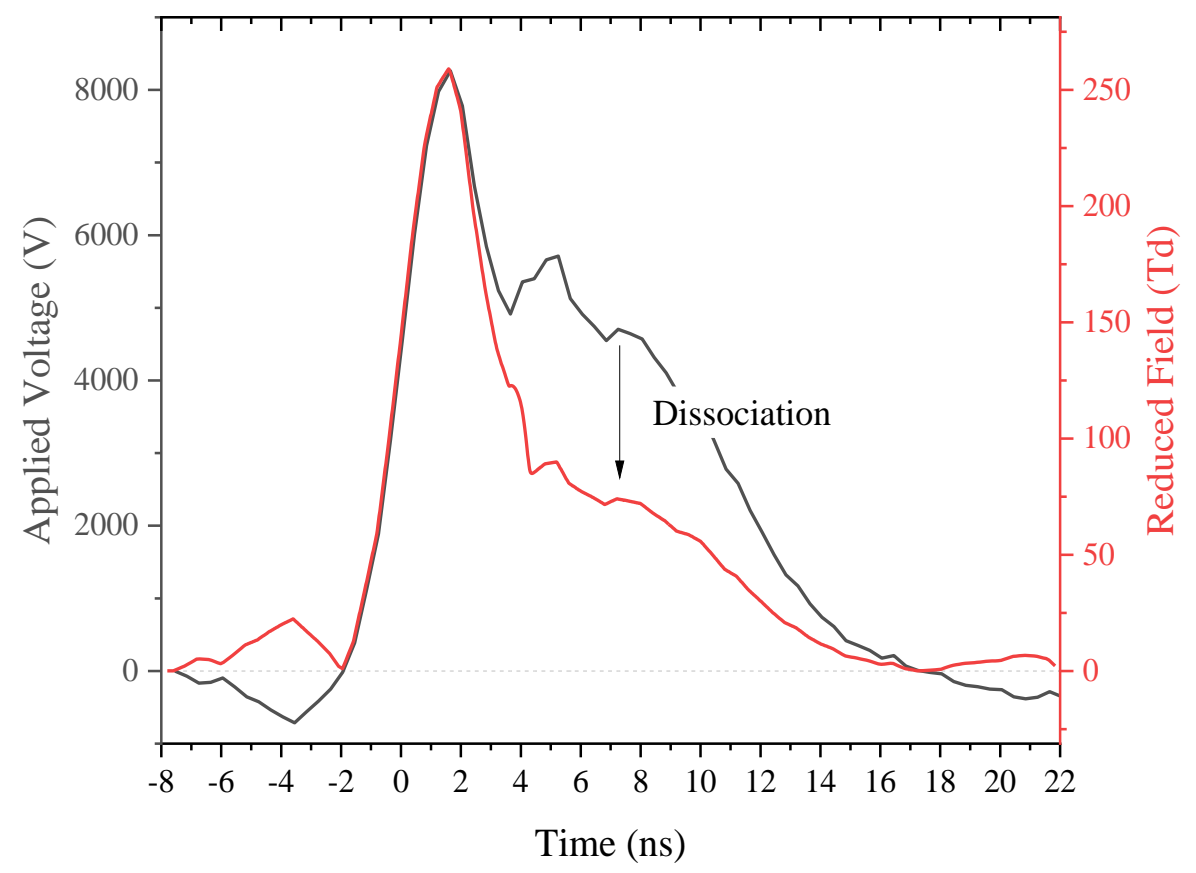

Figure 10 Applied voltage (across the 1.2-mm gap) reconstructed from the difference of incident and reflected voltage (grey line) and reduced field in the simulation (red line).

The applied voltage on the 1.2-mm gap is represented in Figure 10 and was reconstructed from the anode and cathode pulse shapes. The reduced field, E/N, is calculated assuming a Laplacian field between the electrodes. We arbitrarily reduced the reduced field by $6 \%$ to account for the cathode fall (500 V at maximal applied voltage). The reduced field is not strictly proportional to the applied voltage because dissociation of $\mathrm{N}_{2}$ and $\mathrm{O}_{2}$ increases the gas number density. In BOLSIG+, the reduced field $\mathrm{E} / \mathrm{N}$ is defined as the ratio of the electric field to the neutral particle density, $\mathrm{N}_{\text {neutral }}$. However, the neutral particle number density can drop to negligible values. Thus, the reduced field tends toward infinity and the electron temperature increases above reasonable values. Therefore, we define $\mathrm{N}$ as the heavy particle density, i.e. $\mathrm{N}=\mathrm{N}_{\text {ion }}+\mathrm{N}_{\text {neutral }}[34,35]$. 


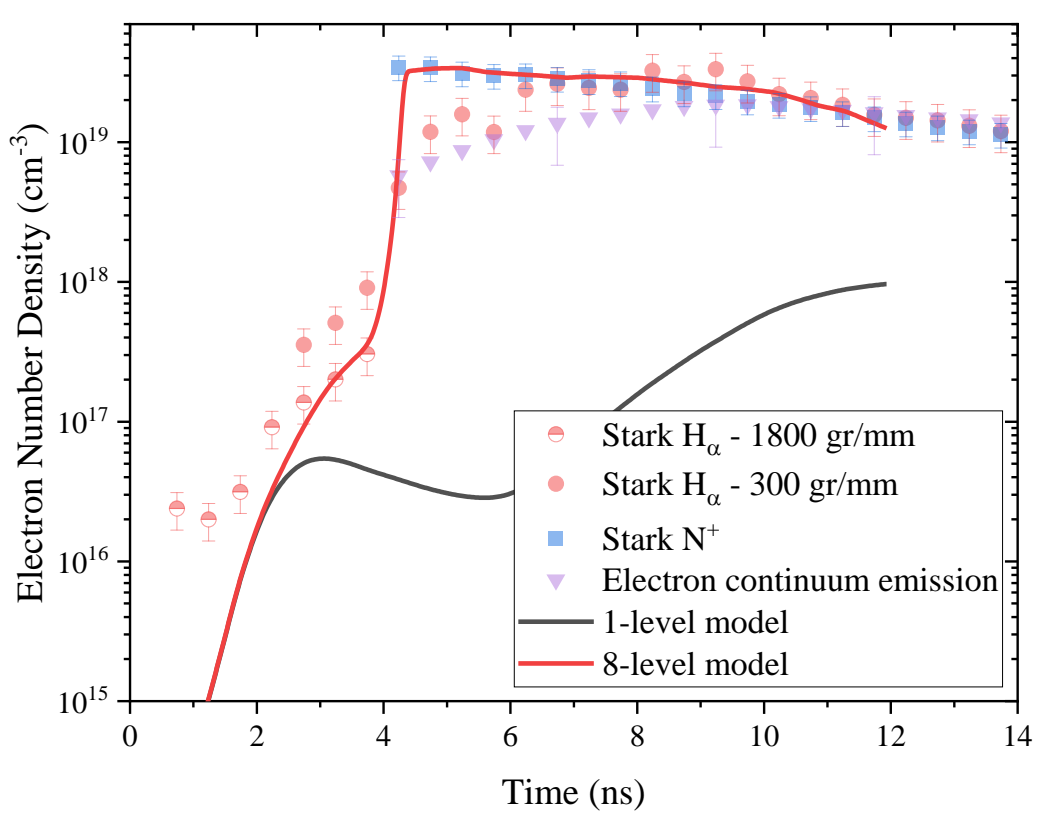

Figure 11 Comparison of the electron number density obtained by simulation (red solid line) with that measured by Stark broadening and continuum emission. If the simulation is run without the ionization of $\mathrm{O}$ and $\mathrm{N}$ excited states (grey solid line), full ionization is not reached.

Figure 11 compares the evolution of the electron number density measured with Stark broadening of $\mathrm{N}^{+}$, Stark broadening of $\mathrm{H}_{\alpha}$, and the free-free/free-bound continuum, with the electron number density calculated with our kinetic mechanism. The "1-level model" includes only the ionization of $\mathrm{N}_{2}$ excited states, Reac. 1, and the electron-impact ionization of $\mathrm{N}$ and $\mathrm{O}$ ground states. In this case, $n_{e}$ reaches at most $10^{18} \mathrm{~cm}^{-3}$ at the end of the $10-\mathrm{ns}$ pulse.

With the "8-level model" the electron-impact ionization of the first eight electronic states of $\mathrm{N}$ and three electronic states of $\mathrm{O}$ are added (i.e. including Reac. 1, Reac. 2, and Reac. 3). For $t<4 \mathrm{ns,} \mathrm{in} \mathrm{the} \mathrm{"8-level} \mathrm{model",} \mathrm{the} \mathrm{production}$ of electrons is primarily due to the ionization of $\mathrm{N}_{2}$ excited states. Then, at $t \approx 4 \mathrm{~ns}$, enough $\mathrm{N}_{2}$ molecules are dissociated, $\mathrm{N}^{+}$ions are produced through stepwise ionization of $\mathrm{N}$, and full ionization is reached. This ionization phase is very abrupt, as reported in the experiments, even though the applied field is decreasing at this instant. The simulation is stopped at $t=12 \mathrm{~ns}$.

The decay of $n_{e}$ at later times is due to an isentropic expansion during at least $100 \mathrm{~ns}$ [9,13]. In these simulations, it was assumed that the process is isochoric, which is usually correct in non-thermal nanosecond discharge. We believe the agreement would be improved if the model would include the plasma channel expansion, which could begin as early as $t=5 \mathrm{~ns}$, see also Figure 8 . The inclusion of the radiative loss, which could be non-negligible, would also represent an improvement. The radiative loss by continuum radiation of the electrons and black body emission is, for instance, included in arc discharge models [47].

\section{Conclusions and future work}

In this work, we study the formation of thermal sparks generated at ambient conditions by an 8-kV pulse of $10 \mathrm{~ns}$ accros a 1.2-mm gap. Near the cathode, we measure the increase of the electron number density using several methods relying on optical emission spectroscopy. First, the Stark broadening of $\mathrm{H}_{\alpha}$, at $656 \mathrm{~nm}$, and $\mathrm{N}^{+}$, at $500 \mathrm{~nm}$, are used. Then, after calibration of the emission spectrum near $\lambda=500 \mathrm{~nm}$, we use the continuum radiation of the electron to infer their number density. Assuming the electronic states of $\mathrm{N}^{+}$and $\mathrm{O}^{+}$are in a Boltzmann equilibrium, we get the ion number density, equal to the electron number density. These four measurements of $n_{e}$ are in agreement and confirm that the thermal spark's full ionization occurs on a timescale of $0.5 \mathrm{~ns}$. In a second part, we demonstrate using a 0-D 
kinetic mechanism that this abrupt ionization can be reproduced if the electron impact ionization of $\mathrm{O}$ and $\mathrm{N}$ excited states are included.

The agreement between simulations and experiments strongly supports the role of the atomic excited states in the ionization of the thermal spark filaments (steps 2 and 3 of the thermal spark formation). However, other questions remain. As future work, we aim to determine which process triggers the cathode filament generation before the anode one. Also, electron-impact ionization of $\mathrm{N}$ and $\mathrm{O}$ excited states should be incorporated in a 1-D or 2-D simulation for a description of the filament propagation.

\section{References}

[1] Pai, D. Z., Lacoste, D. A., and Laux, C. O. "Transitions between Corona, Glow, and Spark Regimes of Nanosecond Repetitively Pulsed Discharges in Air at Atmospheric Pressure." Journal of Applied Physics, Vol. 107, No. 9, 2010, p. 093303. https://doi.org/10.1063/1.3309758.

[2] Macheret, S. O., Shneider, M. N., and Miles, R. B. "Modeling of Air Plasma Generation by Repetitive HighVoltage Nanosecond Pulses." IEEE Transactions on Plasma Science, Vol. 30, No. 3, 2002, pp. 1301-1314. https://doi.org/10.1109/TPS.2002.802142.

[3] Popov, N. A. "Kinetics of Plasma-Assisted Combustion: Effect of Non-Equilibrium Excitation on the Ignition and Oxidation of Combustible Mixtures." Plasma Sources Science and Technology, Vol. 25, No. 4, 2016, p. 043002. https://doi.org/10.1088/0963-0252/25/4/043002.

[4] Bak, M. S., and Cappelli, M. A. "A Reduced Set of Air Plasma Reactions for Nanosecond Pulsed Plasmas." IEEE Transactions on Plasma Science, Vol. 43, No. 4, 2015, pp. 995-1001. https://doi.org/10.1109/TPS.2015.2409300.

[5] Flitti, A., and Pancheshnyi, S. "Gas Heating in Fast Pulsed Discharges in N 2 -O 2 Mixtures." The European Physical Journal Applied Physics, Vol. 45, No. 2, 2009, p. 21001. https://doi.org/10.1051/epjap/2009011.

[6] Aleksandrov, N. L., Kindysheva, S. V, Nudnova, M. M., and Starikovskiy, A. Y. "Mechanism of Ultra-Fast Heating in a Non-Equilibrium Weakly Ionized Air Discharge Plasma in High Electric Fields." Journal of Physics D: Applied Physics, Vol. 43, No. 25, 2010, p. 255201. https://doi.org/10.1088/0022$3727 / 43 / 25 / 255201$.

[7] Kossyi, I. A., Kostinsky, A. Y., Matveyev, A. A., and Silakov, V. P. "Kinetic Scheme of the Non-Equilibrium Discharge in Nitrogen-Oxygen Mixtures." Plasma Sources Science and Technology, Vol. 1, No. 3, 1992, pp. 207-220. https://doi.org/10.1088/0963-0252/1/3/011.

[8] Capitelli, M., Ferreira, C. M., Gordiets, B. F., and Osipov, A. I. Plasma Kinetics in Atmospheric Gases. Springer Berlin Heidelberg, Berlin, Heidelberg, 2000.

[9] Lo, A., Cessou, A., Lacour, C., Lecordier, B., Boubert, P., Xu, D. A., Laux, C. O., and Vervisch, P. "Streamerto-Spark Transition Initiated by a Nanosecond Overvoltage Pulsed Discharge in Air." Plasma Sources Science and Technology, Vol. 26, No. 4, 2017, p. 45012. https://doi.org/10.1088/1361-6595/aa5c78.

[10] Minesi, N., Stepanyan, S. A., Mariotto, P. B., Stancu, G.-D., and Laux, C. O. "On the Arc Transition Mechanism in Nanosecond Air Discharges." AIAA Scitech 2019 Forum, Vol. 2019, 2019, p. 0463. https://doi.org/10.2514/6.2019-0463.

[11] Verreycken, T., Van Der Horst, R. M., Baede, A. H. F. M., Van Veldhuizen, E. M., and Bruggeman, P. J. "Time and Spatially Resolved LIF of OH in a Plasma Filament in Atmospheric Pressure HeH 2O." Journal of Physics D: Applied Physics, Vol. 45, No. 4, 2012. https://doi.org/10.1088/0022-3727/45/4/045205.

[12] Orriere, T., Moreau, E., and Pai, D. Z. "Ionization and Recombination in Nanosecond Repetitively Pulsed Microplasmas in Air at Atmospheric Pressure." Journal of Physics D: Applied Physics, Vol. 51, No. 49, 2018, p. 494002. https://doi.org/10.1088/1361-6463/aae134.

[13] Minesi, N., Stepanyan, S., Mariotto, P., Stancu, G. D., and Laux, C. O. "Fully Ionized Nanosecond Discharges 
in Air: The Thermal Spark." Plasma Sources Science and Technology, Vol. 29, 2020, p. 85003. https://doi.org/10.1088/1361-6595/ab94d3.

[14] Parkevich, E. V., Medvedev, M. A., Ivanenkov, G. V., Khirianova, A. I., Selyukov, A. S., Agafonov, A. V., Korneev, P. A., Gus'Kov, S. Y., and Mingaleev, A. R. "Fast Fine-Scale Spark Filamentation and Its Effect on the Spark Resistance." Plasma Sources Science and Technology, Vol. 28, No. 09, 2019, p. 095003. https://doi.org/10.1088/1361-6595/ab3768.

[15] Houpt, A. W., and Leonov, S. B. "Charge Transfer in Constricted Form of Surface Barrier Discharge at Atmospheric Pressure." Journal of Thermophysics and Heat Transfer, Vol. 31, 2016, pp. 1-9. https://doi.org/10.2514/1.T4970.

[16] Shcherbanev, S. A., Ding, C., Starikovskaia, S. M., and Popov, N. A. "Filamentary Nanosecond Surface Dielectric Barrier Discharge. Plasma Properties in the Filaments." Plasma Sources Science and Technology, Vol. 28, No. 6, 2019, p. 065013. https://doi.org/10.1088/1361-6595/ab2230.

[17] Dumitrache, C., Gallant, A., Minesi, N., Stepanyan, S., Stancu, G. D., and Laux, C. O. "Hydrodynamic Regimes Induced by Nanosecond Pulsed Discharges in Air: Mechanism of Vorticity Generation." Journal of Physics D: Applied Physics, Vol. 52, No. 36, 2019, p. 364001. https://doi.org/10.1088/1361-6463/ab28f9.

[18] Stepanyan, S., Minesi, N., Tibère-Inglesse, A., Salmon, A., Stancu, G. D., and Laux, C. O. "Spatial Evolution of the Plasma Kernel Produced by Nanosecond Discharges in Air." Journal of Physics D: Applied Physics, Vol. 52, No. 29, 2019, p. 295203. https://doi.org/10.1088/1361-6463/ab1ba4.

[19] Cont-Bernard, D. Del, Ruchkina, M., Ding, P., Bood, J., Ehn, A., and Lacoste, D. A. "Femtosecond TwoPhoton Laser-Induced Fluorescence Imaging of Atomic Hydrogen in a Laminar Methane-Air Flame Assisted by Nanosecond Repetitively Pulsed Discharges." Plasma Sources Science and Technology, Vol. 29, No. 6, 2020, p. 065011. https://doi.org/10.1088/1361-6595/ab9234.

[20] Griem, H. R. Plasma Spectroscopy. McGraw-Hill Book Company, New York, 1964.

[21] Laux, C. O., Spence, T. G., Kruger, C. H., and Zare, R. N. "Optical Diagnostics of Atmospheric Pressure Air Plasmas." Plasma Sources Science and Technology, Vol. 12, 2003, pp. 125-138. https://doi.org/10.1088/09630252/12/2/301.

[22] Gigosos, M. A., González, M. Á., and Cardeñoso, V. "Computer Simulated Balmer-Alpha, -Beta and -Gamma Stark Line Profiles for Non-Equilibrium Plasmas Diagnostics." Spectrochimica Acta - Part B Atomic Spectroscopy, Vol. 58, No. 8, 2003, pp. 1489-1504. https://doi.org/10.1016/S0584-8547(03)00097-1.

[23] Konjević, N., Ivković, M., and Sakan, N. "Hydrogen Balmer Lines for Low Electron Number Density Plasma Diagnostics." Spectrochimica Acta Part B: Atomic Spectroscopy, Vol. 76, 2012, pp. 16-26. https://doi.org/10.1016/J.SAB.2012.06.026.

[24] Bastien, F., and Marode, E. "Stark Broadening of $\mathrm{H} \alpha$ and $\mathrm{H} \beta$ in Ionized Gases with Space-Charge Field." Journal of Quantitative Spectroscopy and Radiative Transfer, Vol. 17, No. 4, 1977, pp. 453-469. https://doi.org/10.1016/0022-4073(77)90093-0.

[25] Sher, E., Ben-Ya'ish, J., and Kravchik, T. "On the Birth of Spark Channels." Combustion and flame, Vol. 89, No. 2, 1992, pp. 186-194. https://doi.org/10.1016/S0304-419X(01)00029-4.

[26] www.spectralfit.com. [Online] Specair 3.0. http://www.spectralfit.com.

[27] Orriere, T. Confinement Micrométrique Des Décharges Pulsées Nanosecondes Dans l'air à Pression Atmosphérique et Effets Électro-Aérodynamiques. Université de Poitiers, PhD Thesis, in French, 2018.

[28] De Giacomo, A., Gaudiuso, R., Dell'Aglio, M., and Santagata, A. "The Role of Continuum Radiation in Laser Induced Plasma Spectroscopy.” Spectrochimica Acta - Part B Atomic Spectroscopy, Vol. 65, No. 5, 2010, pp. 385-394. https://doi.org/10.1016/j.sab.2010.03.016.

[29] Bastiaans, G. J., and Mangold, R. A. "The Calculation of Electron Density and Temperature in Ar Spectroscopic Plasmas from Continuum and Line Spectra." Spectrochimica Acta Part B: Atomic Spectroscopy, 
Vol. 40, No. 7, 1985, pp. 885-892. https://doi.org/10.1016/0584-8547(85)80059-8.

[30] Iordanova, E., Palomares, J. M., Gamero, A., Sola, A., and van der Mullen, J. J. A. M. "A Novel Method to Determine the Electron Temperature and Density from the Absolute Intensity of Line and Continuum Emission: Application to Atmospheric Microwave Induced Ar Plasmas." Journal of Physics D: Applied Physics, Vol. 42, No. 15, 2009, p. 155208. https://doi.org/10.1088/0022-3727/42/15/155208.

[31] Wilbers, A. T. M., Kroesen, G. M. W., Timmermans, C. J., and Schram, D. C. "The Continuum Emission of an Arc Plasma." Journal of Quantitative Spectroscopy and Radiative Transfer, Vol. 45, No. 1, 1991, pp. 1-10. https://doi.org/10.1016/0022-4073(91)90076-3.

[32] Sutherland, R. S. "Accurate Free-Free Gaunt Factors for Astrophysical Plasmas." Monthly Notices of the Royal Astronomical Society, Vol. 300, No. 2, 1998, pp. 321-330. https://doi.org/10.1046/j.1365-8711.1998.01687.x.

[33] Karzas, W. J., and Latter, R. "Electron Radiative Transitions in a Coulomb Field." The Astrophysical Journal Supplement Series, Vol. 6, 1961, p. 167. https://doi.org/10.1086/190063.

[34] Minesi, N., Mariotto, P., Stancu, G. D., and Laux, C. O. "Role of the Excited Electronic States in the Ionization of Ambient Air by a Nanosecond Discharge." AIAA Scitech 2020 Forum, Vol. 2020, 2020, p. 0437. https://doi.org/10.2514/6.2020-0437.

[35] Minesi, N., Mariotto, P., Stancu, G. D., and Laux, C. O. "The Role of Excited Electronic States in Ambient Air Ionization by a Nanosecond Discharge." Submitted to: Plasma Sources Science and Technology, 2020.

[36] Minesi, N. Thermal Spark Formation and Plasma-Assisted Combustion by Nanosecond Repetitive Discharges. Université Paris-Saclay, Ph.D. Thesis, 2020.

[37] Park, C. "Review of Chemical-Kinetic Problems of Future NASA Missions, I: Earth Entries." Journal of Thermophysics and Heat Transfer, Vol. 7, No. 3, 1993, pp. 385-398. https://doi.org/10.2514/3.431.

[38] Laux, C., Yu, L., Packan, D. M., Gessman, R. J., Pierrot, L., Kruger, C. H., and Zare, R. "Ionization Mechanisms in Two-Temperature Air Plasmas." 30th Plasmadynamic and Lasers Conference, Nos. 99-3476, 1999. https://doi.org/10.2514/6.1999-3476.

[39] Bacri, J., and Medani, A. "Electron Diatomic Molecule Weighted Total Cross Section Calculation. III. Main Inelastic Processes for $\mathrm{N} 2$ and N2+." Physica $B+C$, Vol. 112, No. 1, 1982, pp. 101-118. https://doi.org/10.1016/0378-4363(82)90136-X.

[40] Popov, N. A. "Pulsed Nanosecond Discharge in Air at High Specific Deposited Energy: Fast Gas Heating and Active Particle Production." Plasma Sources Science and Technology, Vol. 25, No. 4, 2016, p. 44003. https://doi.org/10.1088/0963-0252/25/4/044003.

[41] Tayal, S. S., and Zatsarinny, O. "B -Spline R -Matrix-with-Pseudostates Approach for Excitation and Ionization of Atomic Oxygen by Electron Collisions." Physical Review A, Vol. 94, No. 4, 2016, pp. 1-15. https://doi.org/10.1103/PhysRevA.94.042707.

[42] Wang, Y., Zatsarinny, O., and Bartschat, K. "B-Spline R-Matrix-with-Pseudostates Calculations for ElectronImpact Excitation and Ionization of Nitrogen." Physical Review A, Vol. 89, No. 6, 2014, p. 062714. https://doi.org/10.1103/PhysRevA.89.062714.

[43] Ciccarino, C. J., and Savin, D. W. "Electron-Impact Ionization of Atomic Nitrogen." Journal of Thermophysics and Heat Transfer, Vol. 33, No. 1, 2019, pp. 154-162. https://doi.org/10.2514/1.T5463.

[44] Pancheshnyi, S. V, Eismann, B., Hagelaar, G. J. M., and Pitchford, L. C. Computer Code ZDPlasKin. http://www.zdplaskin.laplace.univ-tlse.fr.

[45] Hagelaar, G. J. M. "Coulomb Collisions in the Boltzmann Equation for Electrons in Low-Temperature Gas Discharge Plasmas." Plasma Sources Science and Technology, Vol. 25, No. 1, 2016, p. 015015. https://doi.org/10.1088/0963-0252/25/1/015015.

[46] Hagelaar, G. J. M., and Pitchford, L. C. "Solving the Boltzmann Equation to Obtain Electron Transport 
Coefficients and Rate Coefficients for Fluid Models." Plasma Sources Science and Technology, Vol. 14, No. 4, 2005, pp. 722-733. https://doi.org/10.1088/0963-0252/14/4/011.

[47] Shneider, M. N. "Turbulent Decay of After-Spark Channels." Physics of Plasmas, Vol. 13, No. 7, 2006, pp. 111. https://doi.org/10.1063/1.2218492.

[48] Dere, K. P., Landi, E., Mason, H. E., Monsignori Fossi, B. C., and Young, P. R. "CHIANTI - an Atomic Database for Emission Lines." Astronomy and Astrophysics Supplement Series, Vol. 125, No. 1, 1997, pp. 149-173. https://doi.org/10.1051/aas:1997368.

[49] Dere, K. P., Zanna, G. Del, Young, P. R., Landi, E., and Sutherland, R. S. "CHIANTI—An Atomic Database for Emission Lines. XV. Version 9, Improvements for the X-Ray Satellite Lines." The Astrophysical Journal Supplement Series, Vol. 241, No. 2, 2019, p. 22. https://doi.org/10.3847/1538-4365/ab05cf.

[50] Verner, D. A., Ferland, G. J., Korista, K. T., and Yakovlev, D. G. "Atomic Data for Astrophysics. II. New Analytic FITS for Photoionization Cross Sections of Atoms and Ions." The Astrophysical Journal, Vol. 465, 1996, p. 487. https://doi.org/10.1086/177435. 